\title{
OS REFUGIADOS NO BRASIL E AS ORGANIZAÇÕES NÃO GOVERNAMENTAIS
}

\section{REFUGEES IN BRAZIL AND THE NON-GOVERNMENTAL ORGANIZATIONS}

\author{
1Jorge Luis Mialhe \\ ${ }^{2}$ Karina Caetano Malheiro
}

\section{RESUMO}

Neste século o fluxo de refugiados e imigrantes tornar-se-á a questão central para o Direito Internacional dos Direitos Humanos. O Brasil, que começou recentemente a receber um fluxo maior de refugiados, é uma opção importante para eles em razão de sua legislação benevolente. No entanto, o Estado brasileiro ainda é relutante quanto ao impacto das recentes levas de refugiados que entram no país sem receber o devido apoio posteriormente. Esta pesquisa dedutiva, na modalidade histórica, pretende analisar o papel pioneiro das ONGs de direitos humanos responsáveis por informar e apoiar os refugiados, oferecendo visibilidade ao tema.

Palavras-chave: Direitos humanos, Direito internacional, Refugiados, Ongs

\begin{abstract}
In this century the flow of refugees and immigrants will become the central issue to International Human Rights Law. Brazil, that recently started to receive a larger flow of refugees, is an important option for them due to its benevolent legislation. However, the Brazilian State is still reluctant concerning the impact of the newly arrived refugees that enter the country without receiving subsequent support. This deductive research, in the historical type, intends to analyze the pioneer role of human rights NGOs responsible for informing and supporting the refugees, offering visibility to the theme.
\end{abstract}

Keywords: Human rights, International law, Refugees, Ngos

\footnotetext{
${ }^{1}$ Doutor em História Social pela Universidade de São Paulo - USP, São Paulo (Brasil). Professor pela Universidade Estadual Paulista Júlio de Mesquita Filho - UNESP, São Paulo (Brasil). E-mail: profmialhe@ @otmail.com

${ }^{2}$ Mestranda em Direito pela Universidade Metodista de Piracicaba - UNIMEP, São Paulo (Brasil).

E-mail: kmalheiro@hotmail.com
} 


\section{Introdução}

O presente artigo, por meio de pesquisa dedutiva, na modalidade histórica pretende analisar o papel pioneiro das ONGs de direitos humanos responsáveis por informar e apoiar os refugiados apresentando as suas origens, a principal convenção sobre a matéria e a sua internalização no direito brasileiro. Ao mesmo tempo, destacará a importância da cooperação entre o ACNUR e as ONGs de direitos humanos para a efetiva proteção dos refugiados que vêm aumentando exponencialmente. ${ }^{1}$

De acordo com o artigo $1^{\circ}$. da Convenção das Nações Unidas Relativa ao Estatuto dos Refugiados das Nações Unidas de 28 de julho de 1951, refugiados são as pessoas que

em conseqüência dos acontecimentos ocorridos antes de $1^{\circ}$ de janeiro de 1951 e temendo ser perseguida por motivos de raça, religião, nacionalidade, grupo social ou opiniões políticas, se encontra fora do país de sua nacionalidade e que não pode ou, em virtude desse temor, não quer valer-se da proteção desse país, ou que, se não tem nacionalidade e se encontra fora do país no qual tinha sua residência habitual em consequiência de tais acontecimentos, não pode ou, devido ao referido temor, não quer voltar a ele. (ONU, 1951, p.1)

Tal Convenção foi aprovada para amparar a atuação do Alto Comissariado das Nações Unidas para Refugiados (ACNUR) criado em 1950, cujos antecedentes remontam a 1921, quando o Conselho da Sociedade das Nações autorizou a criação de um Alto Comissariado para Refugiados voltado, inicialmente, para tratar dos refugiados russos após a revolução bolchevique e dos refugiados armênios na Grécia. (RAMOS, 2011, p.25)

O Brasil somente começou a receber oficialmente refugiados nos termos da Convenção de 1951, após a instalação do escritório regional ad hoc do ACNUR no Rio de Janeiro em 1977. Mas devido à peculiar situação política brasileira à época:

Esse escritório, no entanto, atuou principalmente realizando o reassentamento dos refugiados que ali chegavam, uma vez que, no acordo existente entre o ACNUR e o governo brasileiro, estabelecia-se que o Brasil manteria a limitação geográfica da Convenção de 51, somente recebendo refugiados provenientes da Europa. E, além disso, o Brasil, também vivendo sob uma ditadura militar, não queria dar guarida a pessoas que se opunham a

\footnotetext{
${ }^{1}$ Até agosto de 2015, de acordo com os dados divulgados pelo Ministério da Justiça o Brasil possuía números recordes de refugiados reconhecidos (8.400) e de solicitações de refúgio pendentes de análise (12.666). Disponível em: $\quad$ http://www.acnur.org/t3/portugues/noticias/noticia/ministerio-da-justica-anuncia- fortalecimento-doconare-e-lanca-campanha-de-sensibilizacao/> . Acesso em: 27 mar 2016.
} 
regimes próximos ao seu, mas permitia o trânsito dessas em seu território para reassentamento em outro Estado.

Durante essa fase, cerca de 20 mil argentinos, bolivianos, chilenos e uruguaios foram reassentados na Austrália, Canadá, Europa e Nova Zelândia. ${ }^{2}$ (JUBILUT, 2007, p.171).

Verifica-se que somente com a parceria estabelecida entre o ACNUR e as ONGs, foi possível implementar no Brasil as ações previstas na Convenção de 1951.

De acordo com Jubilut, essa foi uma época em que o ACNUR atuou no Brasil com a ajuda de parceiros não governamentais ${ }^{3}$ tais como "a Cáritas Arquidiocesana do Rio de Janeiro, a Comissão Pontifícia Justiça e Paz (comumente denominada Comissão Justiça e Paz) e a Cáritas Arquidiocesana de São Paulo.” (JUBILUT, 2007, p.172). Em 1982, o ACNUR foi "oficialmente aceito e reconhecido" pelo governo brasileiro e, em 1989, sua sede foi transferida para Brasília. (ANDRADE; MARCOLINI, 2002, p. 37-38)

\section{Refúgio: um breve histórico}

De acordo com o site em inglês do Alto Comissariado das Nações Unidas para Refugiados (ACNUR), existem registros de refúgio há mais de 3.500 anos, desde "o florescimento dos grandes primeiros impérios no Oriente Médio, tais como os Hititas ${ }^{4}$, Babilônios, Assírios e antigos Egípcios."5

No entanto, para efeito do desenvolvimento do instituto do refúgio como conhecemos, devem ser considerados como os primeiros refugiados nos moldes atuais, os judeus expulsos da Espanha a partir da reconquista empreendida pelos reis católicos e que se refugiaram na Itália, Países Baixos e no Império Otomano, bem como os árabes do sul da península ibérica, que emigraram para o Marrocos. (HOURANI, 2001, p. 248-250)

\footnotetext{
${ }^{2}$ O Brasil ratificou e recepcionou a Convenção de 1951 e o Protocolo de 1967, além de fazer parte do Conselho Executivo do ACNUR desde 1958, mas ainda assim, mesmo após a instalação do escritório no Rio de Janeiro, continuou com a reserva geográfica, tendo recebido apesar desta, alguns vietnamitas, cubanos e baha"i entre 1975 e 1980. JUBILUT, 2007, p.172-173.

${ }^{3}$ Andrade e Marcolini explicam que governo brasileiro aceitou a presença do ACNUR, mas não lhe outorgou o status gozado por organizações internacionais. (...) A presença do ACNUR foi oficialmente aceita e reconhecida em 1982. ANDRADE; MARCOLINI, 2002, p.37.

${ }^{4}$ Interessante a nota de Luiz Sales do Nascimento sobre o primeiro tratado de extradição registrado de 1291 a.C., celebrado entre o Faraó Ramsés II e o rei dos Hititas, Hattusillli II, visando justamente evitar que criminosos de ambos os reinos buscassem refúgio entre estes. NASCIMENTO, 2014, p.27, nota 24. O Tratado de Kadesh trazia várias disposições sobre o tema; a título de exemplo, cito uma das cláusulas: "Se um homem foge (ou dois homens desconhecidos) e se foge do rei do país do Egito e não quer servi-lo, então Hattusili, o grande rei, o rei do país hitita deve entregá-lo nas mãos de seu irmão, o rei do Egito, e não deve deixá-lo habitar no país hitita." MIALHE, 2010, p. 226.

5 "Flowing across borders". Disponível em:http://www.unhcr.org/pages/49c3646c125.html. Tradução dos autores. Acesso em: 07 mar 2016.
} 
Da mesma forma, no século XVI, os protestantes dos Países Baixos, e no século XVII, os huguenotes da França ${ }^{6}$ e os quakers e puritanos da Inglaterra anglicana se refugiaram nas colônias norte-americanas. (JUBILUT, 2007, p. 23-24)

Até mesmo um dos pais do Direito das Gentes, Alberico Gentili (1552-1608), italiano convertido ao luteranismo, para fugir da perseguição da Inquisição, procurou proteção e refúgio em vários países da Europa tendo, finalmente, se fixado na Inglaterra onde redigiu o clássico De iure belli libri três e exerceu a docência (regius profesor of civil law) na Universidade de Oxford. (PANIZZA, 2005, p.15-16)

Os exemplos acima são uma pequena amostra da importância do refúgio, normalmente caracterizado na forma de asilo, que mesmo sem ser um direito positivado ${ }^{7}$, sempre foi considerado como essencial nas relações internacionais ${ }^{8}$.Assim, foi por iniciativa da Assembleia Geral das Nações Unidas, que o Alto Comissariado das Nações Unidas para Refugiados (ACNUR $)^{9}$ foi estabelecido em 1950 para um mandato de três anos, tempo considerado à época, suficiente para ajudar as "pessoas deslocadas" em razão da Segunda Guerra Mundial. O ACNUR estendeu suas atividades até que em 1956, quando a Hungria foi

\footnotetext{
${ }^{6}$ Seus destinos foram os mais variados: "Mais ou menos 200.000 huguenotes saíram da França, estabelecendo-se na Europa não católica - os Países Baixos, Alemanha, especialmente Prússia, Suíça, Escandinávia, e mesmo tão longe quanto a Rússia (...) A Companhia Holandesa das Índias Orientais, enviou algumas centenas para o Cabo para desenvolver os vinhedos na África do Sul. Mais ou menos 50.000 vieram para a Inglaterra, talvez com uns 10.000 mudando para a Irlanda.(...) Então, existem muitos habitantes destas ilhas que têm sangue huguenote em suas veias, mesmo se eles usem ou não, alguns dos centenas de nomes franceses daqueles que refugiaram-se aqui - portanto, trazendo a palavra „refugiado“ para a língua Inglesa.” (Tradução dos autores) Disponível em: http://www.huguenotsociety.org.uk/history.html. Acesso em: 14 mar 2016.

${ }^{7}$ De acordo com José H. Fischel de Andrade (1996, p.16), a Constituição Francesa de 1793 foi o primeiro documento da história a positivar o direito de asilo em seu art. 120: “Il donne asile aux étrangers bannis de leur patrie pour la cause de la liberte. Il le refuse aux tyrans".

${ }^{8}$ Hanna Arendt escreve sobre a situação dos milhões de apátridas que surgiram no entre guerras e em virtude da instalação de regimes comunistas e fascistas, informando-nos que "embora o direito de asilo continuasse a funcionar num mundo organizado em Estados-nações e, em certos casos, tenha até sobrevivido às duas guerras mundiais, tornou-se paulatinamente anacrônico, entrando até em conflito com os direitos internacionais do Estado.”. Mais à frente, Arendt explica o dilema dos países de refúgio: "O segundo choque que o mundo europeu sofreu com o surgimento dos refugiados decorria da dupla constatação de que era impossível desfazer-se deles e era impossível transformá-los em cidadãos do país de refúgio" (ARENDT, 2012, p. 384-385), dilema esse, que perdura até hoje.

${ }^{9}$ De acordo com James C. Hathaway, citado pelo Refugee Law Reader, são três as fases do regime moderno dos refugiados internacionais: "1. A primeira fase do reconhecimento coletivo dos refugiados, que vai até a Segunda Guerra Mundial, 2. A segunda fase de transição, que ocorre durante e logo após a Segunda Guerra Mundial, 3. A terceira fase de reconhecimento individual e outras formas de proteção, que começa com o estabelecimento do ACNUR e com a entrada em vigor da Convenção de 1951, continuando até o presente.” BYRNE, 2008, p. 27 (tradução dos autores).
} 
invadida pelas forças do Pacto de Varsóvia. ${ }^{10}$ A partir daquela data, a existência da agência nunca mais foi questionada. ${ }^{11}$

Como foi visto, somente com a Liga das Nações e depois com a Organização das Nações Unidas, que foi estabelecido o instituto do refúgio. Destarte, a explicação de Serraglio sobre a diferença entre refúgio e asilo: "o instituto do refúgio possui aplicabilidade na seara internacional, englobando inclusive, a América Latina quando necessário", enquanto que "o instituto do asilo é empregado no âmbito latino-americano, fundamentado em acordos regionais. (SERRAGLIO, 2014, p. 71)

Assim, como bem sublinhou Flávia Piovesan, o refúgio “é medida essencialmente humanitária, enquanto que o asilo é medida essencialmente política. O refúgio abarca motivos religiosos, raciais, de nacionalidade, de grupo social e de opiniões políticas, enquanto que o asilo abarca apenas crimes de natureza política. Para o refúgio basta o fundado temor de perseguição, enquanto para o asilo há a necessidade de efetiva perseguição" (PIOVESAN, 2001, p.57-68)

Daí, falar-se em refúgio como asilo lato sensu ou em sentido amplo e também em asilo político "o qual se ramifica em asilo territorial e em asilo diplomático" nos países latinoamericanos. (SERRAGLIO, 2014, p. 69)

\section{Convenções sobre refugiados}

A proteção dos refugiados começa com a Liga das Nações, nos termos de um "sistema de proteção internacional” iniciado pelo Comitê Internacional da Cruz Vermelha, em razão da $1^{\text {a }}$ Guerra Mundial e conflitos afins (Guerras dos Balcãs, 1912-1913; Guerras no Cáucaso, 1918-1921; Guerra Greco-Turca, 1919-1922), os quais geraram entre 1 e 2 milhões de refugiados. (JAEGER, 2001, p. 727).

Destarte a criação do Alto Comissariado para Refugiados da Liga das Nações:

\footnotetext{
${ }^{10}$ A Revolução Húngara começou oficialmente quando a Hungria abandonou o Pacto de Varsóvia, estabelecido por Nikita Khruschev como reação à entrada da Alemanha Ocidental na OTAN: "A revolução foi reprimida pelo exército russo em novembro de 1956.’HOBSBAWN, 2009, p. 387.

$11 \mathrm{Na}$ página "A Global Humanitarian Organization of Humble Origins" em http://www.unhcr.org/pages/49c3646cbc.html. Acesso em: 07mar2016.
} 
Visando proteger e assistir os refugiados do Império Otomano e da República Turca, o mandato do Alto Comissariado da Liga das Nações foi estendido aos Armênios em 1924 e "outras categorias de refugiados" (Assírios, Assírio-Caldeus, Sírios, Curdos e um pequeno grupo de Turcos) em 1928. Durante o período da Liga das Nações (1921-1945) várias instituições foram criadas para realizar algumas ou todas as tarefas do Alto Comissariado para Refugiados: o Escritório Internacional Nansen para Refugiados (1931-1938), o Escritório do Alto Comissariado para Refugiados provenientes da Alemanha (1933-1938), o Escritório para o Alto Comissariado da Liga das Nações para Refugiados (1939-1945) e o Comitê Intergovernamental sobre Refugiados (1938-1947). (JAEGER, 2001, p. 729) (tradução dos autores)

Com a Convenção sobre o Status Internacional dos Refugiados de $1933^{12}$, EstadosMembros da Liga das Nações "assumiram obrigações reais em benefício de refugiados Russos, Armênios e assimilados", tornando-se um documento ${ }^{13}$ essencial para a proteção dos refugiados ao dispor sobre questões administrativas e legais, e dando pela primeira vez "status de direito internacional dos tratados" ao princípio do non-refoulement (proibição de retorno forçado de refugiado para país onde este pode vir a sofrer perseguição). (JAEGER, 2001, p. 729-730)

Em 1946 foi estabelecida, já pela Assembléia Geral das Nações Unidas, a Organização Internacional de Refugiados, que "ficou conhecida como uma agência de reassentamento" e que encerrou suas atividades em $1950^{14}$. Como era evidente que a questão dos refugiados se prolongaria, o Conselho Econômico e Social requereu um "Estudo de Apatrídia" que serviria de base para a Convenção de 1951, juntamente com as Convenções anteriores sobre o tema, bem como recomendava a criação de um Alto Comissariado responsável pelos refugiados, o qual daria continuação ao trabalho da Organização Internacional de Refugiados. (JAEGER, 2001, p. 733-735)

\footnotetext{
${ }^{12}$ Foi Convenção ratificada por nove Estados: Bélgica, Bulgária, Dinamarca, França, Grã-Bretanha, Irlanda, Itália, Noruega e Tchecoslováquia. Apêndice da Convenção de 1933 da Liga das Nações. Disponível em: http://www.refworld.org/cgi-bin/texis/vtx/rwmain?docid=3dd8cf374. Acesso em: 03 mar 2016.

13 Dois outros tratados sobre o tema lidaram com refugiados da Alemanha Nazista: o Arranjo Provisional relativo ao status dos Refugiados provenientes da Alemanha de 1936 e a Convenção sobre o Status dos Refugiados provenientes da Alemanha de 1938; sendo que um Protocolo de 1939, ampliava o âmbito de atuação dos documentos citados para incluir refugiados provenientes da Áustria. Nenhum dos tratados, no entanto, sequer "menciona a expressão refoulement, e suas provisões sobre asilo são mais fracas do que aquelas da Convenção de 1933." Traziam inclusive, a possibilidade de devolver refugiados para o Terceiro Reich. (JAEGER, 2001, p. 731)

${ }^{14}$ Gilbert Jaeger nos informa que esta alcunha, advém do reassentamento de "1.049 refugiados e pessoas deslocadas", que foi a principal atividade da organização. (JAEGER, 2001, p. 732)
} 
A Convenção de 1951, também conhecida como Estatuto dos Refugiados, foi adotada em 28 de julho de 1951, com progressivas ratificações desde então; o Escritório do Alto Comissariado das Nações Unidas para Refugiados foi criado pela Assembleia Geral da ONU em 3 de dezembro de 1949 e começou a funcionar oficialmente a partir de $1^{\circ}$ de janeiro de 1951 . (JAEGER, 2001, p. 736)

Juntamente com o Protocolo de 1967, que aumentou sua abrangência, permanece como o documento internacional mais importante na proteção dos refugiados.

\section{O papel do ACNUR}

De acordo com o site do ACNUR, sua missão principal é "assegurar os direitos e o bem-estar dos refugiados.", podendo para tanto, "intervir em benefício de outros grupos de pessoas, entre os quais se destacam: os apátridas; as pessoas cuja nacionalidade é controversa; e as pessoas deslocadas dentro do seu próprio país (os deslocados internos)."

O Estatuto do ACNUR utiliza como parâmetros a Convenção de 1951 (Estatuto dos Refugiados) $)^{16}$ e o Protocolo de 1967 que expandiu a abrangência do Estatuto para outros grupos de deslocados (era limitada aos refugiados até 1951). ${ }^{17}$

O ACNUR tem autorização para:

intervir em benefício de outros grupos de pessoas, entre os quais se destacam: os apátridas; as pessoas cuja nacionalidade é controversa; e as pessoas deslocadas dentro do seu próprio país (os deslocados internos). (...) Em seus esforços para proteger os refugiados e promover soluções duradouras, o ACNUR colabora de modo estreito com governos, organizações regionais e internacionais e organizações não-governamentais (ONGs). ${ }^{18}$

\section{A proteção jurídica dos refugiados no Brasil}

A Lei 9.474/97 reproduz o texto da Convenção Relativa ao Estatuto dos Refugiados das Nações Unidas e traz o conceito de refugiado já em seu artigo $1^{\text {º }}$ :

\footnotetext{
${ }^{15}$ Disponível em: http://www.acnur.org/t3/portugues/informacao-geral/a-missao-do-acnur/. Acesso em: $10 \mathrm{mar}$ 2016.

16 Apesar de o Brasil ter aderido à Convenção em 1952, foi somente após a ratificação com o Decreto $50.215 / 1961$ que passou a fazer parte de nosso ordenamento jurídico, mesmo que com uma reserva geográfica e uma temporal ("acontecimentos ocorridos antes de 1'. De janeiro de 1951 na Europa" ou "na Europa ou alhures") (grifos nossos). Este decreto foi substituído pelo de n. 70.946/1972, que aderiu ao Protocolo de 1967, sem as reservas. NASCIMENTO, 2014, p. 38-39.

${ }_{17}^{17}$ Disponível em: <http://www.adus.org.br/convencao-de-1951/>. Acesso em: 17 fev 2016.

${ }^{18}$ Idem.
} 
Art. $1^{\circ}$ Será reconhecido como refugiado todo indivíduo que:

I - devido a fundados temores de perseguição por motivos de raça, religião, nacionalidade, grupo social ou opiniões políticas encontre-se fora de seu país de nacionalidade e não possa ou não queira acolher-se à proteção de tal país; II - não tendo nacionalidade e estando fora do país onde antes teve sua residência habitual, não possa ou não queira regressar a ele, em função das circunstâncias descritas no inciso anterior;

III - devido a grave e generalizada violação de direitos humanos, é obrigado a deixar seu país de nacionalidade para buscar refúgio em outro país.

Tal conceito, como visto, está em conformidade com todo o arcabouço jurídico internacional de proteção aos refugiados. Assim, conforme o relatório de análise estatística sobre refúgio no Brasil realizado pelo ACNUR de 2010 até outubro de 2014, a lei 9.474/97 utiliza-se da "definição ampliada de refugiado":

\begin{abstract}
A lei adota a definição ampliada de refugiado estabelecida na Declaração de Cartagena de 1984, que considera a "violação generalizada de direitos humanos" como uma das causas de reconhecimento da condição de refugiado. Em maio de 2002, o país ratificou a Convenção das Nações Unidas de 1954 sobre o Estatuto dos Apátridas e, em outubro de 2007, iniciou seu processo de adesão à Convenção da ONU de 1961 para Redução dos Casos de Apatrídia. ${ }^{19}$
\end{abstract}

Também foi criado com o advento da Lei 9.474/97, o Comitê Nacional para os Refugiados (CONARE) ${ }^{20}$, “um órgão interministerial presidido pelo Ministério da Justiça e que lida principalmente com a formulação de políticas para refugiados no país, com a elegibilidade, mas também com a integração local de refugiados.",21

\title{
6. Perfil dos refugiados no Brasil
}

O Brasil não tem uma grande população de apátridas porque nossa Constituição de 1988 adota o princípio de que todos aqueles nascidos em território brasileiro, são

19 Relatório do ACNUR: "Refúgio no Brasil - Uma Análise Estatística: Janeiro de 2010 a Outubro de 2014.”Disponível em: http://www.acnur.org/t3/portugues/recursos/estatisticas/dados-sobre-refugio-no-brasil/. Acesso em: 10 mar 2016.

${ }^{20}$ “'Embora com carências de recursos e de pessoal, e os problemas gerados pelo desconhecimento que o tema dos refugiados ainda enfrenta no Brasil - inclusive dentro da polícia federal - o Conare vem desenvolvendo a contento as suas atribuições e talvez seja um dos órgãos administrativos federais mais eficientes em sua esfera de atuação.Essa característica dá credibilidade a uma política de Estado para os refugiados que se torna apta a fortalecer uma política internacional brasileira nessa matéria.” RODRIGUES, 2010, p.137.

${ }^{21}$ Relatório do ACNUR: "Refúgio no Brasil... 
automaticamente considerados cidadãos brasileiros. ${ }^{22}$ Porém, graças às benesses da Lei 9.474/97, o país tem se tornado um destino viável para refugiados do mundo todo.

Até outubro de 2014, por exemplo, o Brasil tinha 7.289 refugiados reconhecidos de 81 países diferentes, sendo a maioria da Síria (20\% dos pedidos), Colômbia, Angola, República Democrática do Congo, Líbano, Libéria, Palestina, Iraque, Bolívia e Serra Leoa. No período de 2010 a 2013, houve um aumento de 566 pedidos para 5.882, ou seja, um incremento de mais de $900 \%$. Até outubro de 2014, mais 8.302 pedidos foram realizados. O CONARE deferiu até outubro de 2014, 2.032 pedidos contra 150 no ano de $2010 .^{23}$

\section{Organizações Não-Governamentais - a participação da sociedade civil no Brasil}

Foi somente com o art. $71^{24}$ da Carta das Nações Unidas, que a expressão “organização não-governamental" surgiu e a partir daí teve início a regulamentação da atuação destas entidades.

O apoio das organizações não-governamentais tem sido decisivo para a recepção destes refugiados no Brasil, em virtude do pouco interesse das autoridades brasileiras para com eles. Relevante então, examinarmos brevemente como se deu o desenvolvimento das ONGs no país e, examinar essas organizações, é perscrutar sobre o papel da sociedade civil ${ }^{25}$ face ao Estado de Direito.

No Brasil, a sociedade civil começa a organizar-se em definitivo na década de 1970: "O final dos anos 70 destaca-se nesta trajetória porque o termo foi definitivamente introduzido no vocabulário político corrente e passou a ser objeto de elaboração teórica." Com a abertura política nos anos 1980, "surge uma pluralidade de novos atores, decorrentes

\footnotetext{
${ }^{22}$ UNHCR - Relatório de Revisão Periódica Universal da Divisão de Proteção Internacional - Maio 2012. Disponível em: http://www.refworld.org/pdfid/4ed360b12.pdf. Acesso em: 13 mar 2016.
Dados
estatísticos
do
ACNUR
no
Brasil.

Disponível em:

http://www.acnur.org/t3/portugues/recursos/estatisticas/dados-sobre-refugio-no-brasil/. Acesso em: 21 mar 2016. Até o fim da redação do texto, não haviam sido divulgados dados mais atualizados.

${ }^{24}$ Art. 71 - O Conselho Econômico e Social pode realizar arranjos adequados para consulta com organizações não-governamentais, que são relacionadas com assuntos de sua competência (grifos nossos) (tradução dos autores) Disponível em: http://www.un.org/en/documents/charter/chapter10.shtml. Acesso em: 19 mar 2016.

${ }^{25}$ Bobbio oferece um conceito que leva em consideração as instituições pós-modernas e, portanto, mais abrangente: "O que é a sociedade civil?Numa primeira aproximação pode-se dizer que a sociedade civil é o lugar onde surgem e se desenvolvem os conflitos econômicos, sociais, ideológicos, religiosos, que as instituições estatais têm o dever de resolver ou através da mediação ou através da repressão.” BOBBIO, 2014, p. 35.
} 
de novas formas de associativismos que emergem na cena política." É precisamente, na década de 90 que as organizações não-governamentais surgem em quantidade e se estabelecem em definitivo como parte da sociedade brasileira. (GOHN, 2008, p. 70-80).

Especialmente após o advento da Constituição Federal de 1988, as organizações nãogovernamentais se desenvolveram efetivamente, passando a ter "um papel central no processo de consolidação da democracia pela ampliação da esfera pública", afinal "foi a partir da atuação destas organizações na luta em prol dos direitos, de modo particular os coletivos e difusos, pelo reconhecimento jurídico de sua titularidade processual de representação coletiva (legitimação extraordinária)". (SOCZEK, 2007, p. 118)

Essa mudança na esfera pública brasileira iniciada na década de 1980, a partir da redefinição ${ }^{26}$ da participação da sociedade civil, "amplia-se nos anos 90, no sentido de tecer mecanismos que viabilizam a participação e o controle social, sendo as ONGs importantes articuladores deste processo, ao lado de outras formas de organização social.” (SOCZEK, 2007, p. 119)

Assim, as $\mathrm{ONGs}^{27}$ transformaram-se nas últimas duas décadas em sérios empreendimentos da sociedade civil, atuando às vezes em conjunto com o poder público, às vezes de forma pioneira em áreas que, se não ignoradas, meramente menosprezadas pelas instituições estatais tradicionais. ${ }^{28}$ Esse aumento da participação da sociedade na esfera pública, relaciona-se diretamente com a participação democrática: “O crescimento das ONGs denota um aumento do compromisso da sociedade com a cidadania, resultando no

${ }^{26}$ Em tempo o comentário de Manoel Hermes de Lima em sua obra "Organizações Não Governamentais defensoras dos Direitos Humanos: "Nesse processo republicano de valorização, asseguram-se a presença das ONGs e a legitimação da identidade dessas organizações como elementos integrantes da esfera pública pelas suas ações. Por meio da concepção republicana de cidadania, pressupõe-se a possibilidade de se alcançar um consenso, cujo limite é a pretensão de cada ONG identitária exigir um reconhecimento pleno de suas pretensões como exigência de sua própria identidade. O cidadão, que é um participante ativo da configuração da direção futura da sua sociedade por meio do debate e da elaboração de decisões públicas, segue por esta via a perseguição de seu bem-estar.” LIMA, 2014, p. 194.

27 "A esse número de atores transnacionais, - e isto é sobretudo visível no nível global - devemos acrescentar o conjunto das organizações não-governamentais, onde na primeira fileira encontramos aquelas que defendem o meio-ambiente ou promovem a democracia e a proteção dos direitos humanos. Nunca, repetimos, as ONGs foram tão fortes." ARNAUD, 2007, p. 44-45.

${ }^{28}$ Soczek dá ênfase a esta transformação: "As ONGs, ao longo dos anos, agregaram aos seus ideais de emancipação a instrumentalidade necessária para o alcance deste objetivo, como a implementação de infra estrutura via recursos nacionais ou estrangeiros e a busca pelo desenvolvimento de conhecimentos técnicos e recursos humanos cada vez mais qualificados. Dessa forma, sua atuação deixa de ser um mero experimentalismo voluntarista para se transformar em empreendimentos de amplo e profundo impacto social, desenvolvendo um trabalho de qualidade em parceria com órgãos públicos e, também, junto às organizações da esfera do mercado." SOCZEK, 2007, p. 146-147. 
empoderamento social pela conduta em prol da busca e exercício da democracia." (SOCZEK, 2007, p. 147)

\section{ONGs para refugiados: desafios}

Como foi visto anteriormente, apesar de juridicamente o Brasil ter sempre apoiado todas as formas de proteção internacional ao refugiado, em termos factíveis, sempre foi pequena sua contribuição ao refúgio. Inicialmente, porque com as reservas impostas à Convenção de 1951, praticamente só poderia receber refugiados europeus que buscassem "santuário" em virtude da $2^{a}$ Guerra Mundial.

Mesmo após a ratificação do Protocolo de 1967, excluindo as reservas, continuou tímida a participação brasileira no oferecimento de refúgio em razão da ditadura militar de direita instalada no país até meados dos anos 1980.

Apesar da Associação Brasileira de Organizações Não-Governamentais (ABONG), não especificar quais ONGs realizam no Brasil trabalhos junto a refugiados, optou-se por aquelas com maior visibilidade, tanto na mídia quanto entre os refugiados, visando oferecer um panorama da posição da sociedade brasileira face ao tema. ${ }^{29}$

Foi justamente através da intervenção de uma organização não-governamental, a Cáritas $^{30}$ sob a coordenação das Arquidioceses do Rio de Janeiro e de São Paulo, que os primeiros refugiados não europeus chegaram ao Brasil entre 1975 e $1980 .^{31}$

A Cáritas é uma sociedade civil de direito privado criada em 1956 pela Conferência Nacional dos Bispos do Brasil (CNBB) e tem atuado significativamente na orientação e no acompanhamento dos refugiados no Brasil. É uma das poucas entidades que prestam serviços de acolhida e integração a refugiados no Brasil. A Cáritas, além de contar com inúmeros

\footnotetext{
${ }^{29}$ De acordo com Gilberto M. A. Rodrigues, "há uma Rede Solidária de Proteção a Migrantes e Refugiados formada por cerca de 50 instituições da sociedade civil nas cinco regiões do país. Dentre estas organizações, cabe destacar o Instituto Migrações e Direitos Humanos (IMDH), que tem exercido liderança no debate e nas ações da sociedade civil." RODRIGUES, 2010, p. 138. Os membros desta "Rede Solidária" estão disponíveis na páginahttp://migrante.org.br/index.php/membros-da-rede-solidaria.Acesso em: 21 mar2016.

${ }^{30}$ De acordo com a cartilha de organização das ações caritas: "A Cáritas, na sua estrutura e organização jurídica, tem procurado identificar-se como uma Entidade Beneficente de Assistência Social (Ebas), sem fins lucrativos, de acordo com a Lei Orgânica de Assistência Social (Loas).” POLETTO; ADAMS, 2005, p. 19.

${ }^{31}$ Foram recebidos alguns vietnamitas, cubanos e baha"i neste período. JUBILUT, 2007, p. 173.
} 
parceiros, conta com o ACNUR ${ }^{32}$ e com o Ministério da Justiça para a realização dos programas de acolhimento, proteção legal e integração local. (CÁRITAS, 2016)

A Cáritas conta com equipes técnicas formadas por assistentes sociais, advogados, psicólogos e voluntários que prestam atendimento aos solicitantes de refúgio e refugiados, com vistas a contribuir no processo de reconstrução de suas vidas em nosso país. Os refugiados recebem apoio jurídico, psicológico e social por meio de atividades de orientação jurídica diversa, acompanhamento das solicitações de refúgio e encaminhamentos para instituições afins; atendimento psicológico individual e em grupo; curso de português e orientação e encaminhamentos nas áreas de trabalho, educação, saúde, documentação, capacitação profissional, cultura e lazer e geração de renda, com o objetivo de facilitar sua integração na sociedade brasileira. Para tal são realizados atendimentos individuais, atendimentos multiprofissionais, reuniões com refugiados, visitas domiciliares e divulgação sobre a temática do refúgio em instituições de saúde, educação, empresas e na mídia em geral com fins a combater o preconceito e possibilitar o acesso a seus direitos. Importante ressaltar que, ao longo dos anos, a Cáritas vem estabelecendo parcerias estratégicas com diferentes instituições que vem formando uma rede de proteção voltada para apoiar a proteção legal e a integração local dos(as) refugiados(as) no Brasil. (CÁRITAS, 2016)

Independentemente da natureza jurídica, a Cáritas se ajusta perfeitamente ao papel das ONGs:

\begin{abstract}
As ONGs, em paralelo a outras formas de organização da sociedade, cumprem um papel fundamental de atenção a estas demandas sociais, ou seja, todo um contingente populacional de grande envergadura que não consegue usufruir dos direitos e exercer seus deveres assegurados por lei a todas as pessoas. Quando estas organizações avançam sobre as causas dos problemas sociais, reivindicam que tais direitos sejam cumpridos e universalizados pelo poder público. Apontam deficiências e se fazem ouvir aos geralmente moucos ouvidos governamentais no que diz respeito à exclusão social, ao desrespeito aos direitos humanos, preservação ambiental e outros, contrariando interesses enraizados nas estruturas de poder. (SOCZEK, 2007, p. 155)
\end{abstract}

Na cidade de São Paulo, a ONG ADUS - Instituto de Reintegração do Refugiado tem desenvolve parceira com o ACNUR no Brasil e oferece ajuda ao refugiado, solicitante de refúgio e pessoa em situação análoga ao refúgio, através de programas para integração na

\footnotetext{
32 Em 2014, o ACNUR, juntamente com as "organizações da sociedade civil”": as Cáritas Arquidiocesanas do Rio de Janeiro e de São Paulo, o Instituto Migrações e Direitos Humanos, a Associação Antônio Vieira e o Centro de Defesa dos Direitos Humanos de Guarulhos, lançaram a "Cartilha para Refugiados no Brasil", contendo "Direitos e Deveres, Documentação, Soluções Duradouras e Contatos Úteis". Na Cartilha constam as informações básicas para os refugiados, em Português, Inglês, Francês, Espanhol e Árabe. Disponível em: http://www.acnur.org/t3/fileadmin/scripts/doc.php?file=t3/fileadmin/Documentos/portugues/Publicacoes/2014/C artilha_para_refugiados no_Brasil. Acesso em: 10 mar 2016.
} 
sociedade brasileira que envolve a valorização do refugiado e sua “inserção social, econômica e cultural." 33 De acordo com comunicação oficial do Instituto, os maiores desafios são a própria manutenção da ONG, realizada com trabalho voluntário e doações e a obtenção de documentação para o refugiado que possibilite sua inserção no mercado de trabalho.

Dentre os seus programas, destaca-se o de Advocacy, cujo objetivo estratégico é “entender com propriedade a situação atual do refúgio no Brasil e no mundo, através de pesquisas, momentos de discussão e debates sobre o tema, com a participação ativa dos beneficiários do programa." Tem como objetivos específicos "aprofundar o aprendizado e produzir conhecimento sobre o tema do Refúgio para a equipe de Advocacy", desenvolvendo as seguintes atividades:

\begin{abstract}
Organizar encontros com especialistas, policy makers e refugiados sobre o tema do Refúgio no Brasil e no mundo; promover imersão da equipe de advocacy nos programas do Adus; estabelecer Grupos de Trabalho (GTs) para discussões quinzenais sobre temas específicos dentro da questão do refúgio; monitorar atualidades e políticas públicas já existentes sobre o tema do refúgio no Brasil, bem como compreender a situação política e econômica nos países de origem dos refugiados; preparar o Relatório Anual de Advocacy do ADUS sobre o tema do refúgio no Brasil; definir as causas que o ADUS defenderá; construir estratégias para o enfrentamento da causa apresentada; lutar pela causa (enfrentamento) através de iniciativas políticas e de campanhas de conscientização; apresentar dos resultados para sociedade civil e mídia através de campanhas e relatório; promover iniciativas que facilitem a reintegração e vida dos refugiados no Brasil, a partir da priorização de causas para enfrentamento junto aos atores envolvidos. (ADUS, 2016)
\end{abstract}

Outra ONG que apoia os refugiados é a BibliASPA - Biblioteca e Centro de Pesquisa América do Sul - Países Árabes, também da cidade de São Paulo. Trata-se de

um centro de pesquisa e cultura criado com o objetivo de promover a reflexão crítica por meio da pesquisa, produção e difusão sobre os povos árabes, africanos e sul-americanos. Para isso, congrega pesquisadores e acadêmicos de mais de 40 países e desenvolve cursos de língua, cultura, literatura, história, arqueologia, caligrafia etc., exposições, festival de arte, publicação de livros, pesquisas, consultoria para projetos especiais, mostras de cinema e teatro, bibliotecas especializadas e saraus, entre outras ações. (BIBLIASPA, 2016)

Portanto, a BibliASPA é um "centro de pesquisa e de cultura dedicado a temas árabes, africanos e sul-americanos" que oferece cursos de português para refugiados (sírios,

${ }^{33}$ ADUS - Instituto de Reintegração do Refugiado-Brasil. Disponível em: http://www.adus.org.br/. Acesso em: 17 fev 2016. 
iraquianos, palestinos, sudaneses, marfinenses, senegaleses, nigerianos, congoleses, bolivianos, ganenses etc.) de qualquer nacionalidade. ${ }^{34}$ Trabalho importante, visto que, a língua é o maior desafio para os refugiados em geral. ${ }^{35}$ Bem como o núcleo de pesquisa "Refugiados no Brasil e no Mundo", que comporta várias linhas de pesquisa sobre o tema, entre elas educação, inserção na sociedade brasileira dos refugiados, direitos humanos e aspectos jurídicos e política externa do Brasil. ${ }^{36}$

Em Uberlândia (MG), a ONG IKMR - I know my rights, oferece apoio à criança refugiada. De acordo com o site, a $\mathrm{ONG}$ "é a única que se dedica especificamente às crianças refugiadas, sendo regida pelas disposições contidas na Convenção Internacional dos Direitos das Crianças, no Estatuto da Criança e do Adolescente, na Convenção de Genebra de 1951 e seu Protocolo de 1967, na Declaração de Cartagena, bem como a Declaração e o Plano do México, a Lei $9474 / 97^{37}$ e as resoluções do Comitê Nacional para Refugiados (CONARE). Todo o financiamento da IKMR é proveniente de doações de indivíduos e da iniciativa privada, o que viabiliza sua autonomia financeira”. ${ }^{38}$

Para a IKMR, a criança solicitante de refúgio "é aquela que pertence a um núcleo familiar estrangeiro, que se considera vítima de perseguição em seu país de origem e solicita formalmente a proteção do governo brasileiro." A ONG, informa também que segundo dados do CONARE “do total de solicitações de refúgio de 2012, 6\% foram de menores de 18 anos, dos quais $36 \%$ correspondem a crianças entre zero e cinco anos. ${ }^{39}$

Dentre os seus objetivos específicos destacam-se medidas para:

beneficiar crianças solicitantes de refúgio e refugiadas, em situação de privação, exclusão e vulnerabilidade social; promover a defesa e agir pelo cumprimento dos direitos das crianças solicitantes de refúgio e refugiadas no

\footnotetext{
${ }^{34}$ Disponível em: http://bibliaspa.org/educacao/cursos/. Acesso em: 07 mar 2016.

${ }^{35}$ Ao comentar sobre um refugiado sírio no Brasil, a reportagem "Bem Vindos ao Brasil...e virem-se" da Revista Veja informa: "A língua tem sido a maior barreira para que eles possam ganhar independência. Esse é o caso de Maher Hamoudeh, de 32 anos. Fugindo da guerra civil que obrigou 4 milhões de pessoas a sair da Síria, ele deixou a cidade de Artuz com a mulher e as três filhas (de 1, 7 e 9 anos) em 2014 para tentar a sorte no Brasil." COUTINHO, Leonardo. Bem vindos ao Brasil...e virem-se .Veja. São Paulo: Editora Abril, edição 2429, ano 48, n. 23, 10 jun 2015, p. 94-95.

${ }^{36}$ Disponível em: http://bibliaspa.org/refugiados/pesquisa/. Acesso em 07 mar 2016.

${ }^{37} \mathrm{O}$ site da ONG IKMR, afirma que a "legislação brasileira sobre refúgio é considerada pela ONU como uma das mais modernas, abrangentes e generosas do mundo, por ter sido escrita sob a ótica dos direitos humanos, e não sob o prisma do direito penal, e por contemplar todos os dispositivos de proteção internacional de refugiados. A chave do êxito do esforço brasileiro de acolhida aos solicitantes de refúgio e aos refugiados que buscam nossa pátria é o tripartitismo, modelo estabelecido pela Lei 9.474/1997 de trabalho compartilhado pela sociedade civil organizada, pelo ACNUR e pelo Estado brasileiro em prol do refúgio." Disponível em: http://www.ikmr.org.br/refugio/refugio-no-brasil/. Acesso em: 07 mar 2016.

${ }_{39}$ Disponível em: http://www.ikmr.org.br/criancas/criancas-no-brasil/. Acesso em: 07 mar 2016.

${ }^{39}$ Idem.
} 
Brasil até doze anos incompletos; atuar como centro unificador, produtor e difusor de conteúdo legítimo diante da sociedade civil, que sirva ao propósito de esclarecer, informar, mobilizar e influenciar políticas públicas em prol das crianças solicitantes de refúgio e refugiadas no Brasil; contribuir e atuar junto ao poder público no sentido de pensar medidas de proteção, cuja execução tenha como finalidade o bem estar das crianças solicitantes de refúgio e refugiadas no Brasil, por meio da criação e do monitoramento de políticas públicas adequadas; desenvolver e trabalhar junto a outras instituições, promovendo e construindo parcerias que garantam a proteção dos direitos de cada criança solicitante de refúgio e refugiada no Brasil. (IKMR, 2016)

De acordo com Marcelo Haydu (2011, p.140), o Brasil possui “ a maior rede de suporte a refugiados da América Latina, com aproximadamente 100 organizações locais envolvidos, tendo no Instituto Migrações e Direitos Humanos - IMDH o ponto focal desta rede. Em geral, os refugiados se beneficiam dos serviços sociais básicos”. Porém, como bem ressaltou o mesmo autor,

os solicitantes de refúgio e refugiados têm encontrado dificuldades em ter acesso a serviços públicos básicos, sobretudo cuidados médicos e moradias. Além disso, eles também se sentem discriminados pela sociedade local. Por falta de campanhas consistentes e de informação, grande parte da população brasileira não sabe ao certo quem é um refugiado e com frequiência os reconhece como fugitivos da justiça, tornando a integração na sociedade e no mercado de trabalho ainda mais difícil (HAYDU, 2011, p.143)

Como bem destacaram Annoni e Valdes (2013, p.170), “o problema dos refugiados não se deve a ausência de leis, tratados, convenções e estatutos, mas sim, ao descaso dos Estados, que apesar de aderirem a esses institutos, não honram seus compromissos”.

Verifica-se, portanto, que a sociedade civil se organiza para preencher lacunas, seja com o trabalho das ONGs, seja em parcerias com instituições estatais, visando o bem estar destes refugiados. Por isso, extremamente relevante o trabalho destas ONGs solidárias com a condição dos refugiados no Brasil.

\section{Considerações finais}

O mundo neste início de milênio tornou-se menor em termos de distâncias e mais complexo em termos geopolíticos. Os refugiados tornaram-se um problema global, com números crescentes a cada ano e atualmente, passaram a ser um problema também do Brasil. 
Como o Brasil tem uma legislação bastante liberal quanto ao recebimento dos refugiados em geral, o país torna-se a cada dia uma opção relevante para os refugiados num cenário mundial cada vez mais excludente. Assim, considerando o enrijecimento das legislações sobre imigração nos países europeus e nos Estados Unidos, a tendência será a de receberemos cada vez mais imigrantes e refugiados.

Nunca recebemos tantos refugiados, nem fomos tão procurados como país de refúgio. A evolução de nossa legislação foi decisiva para essa mudança, bem como o acirramento à entrada destes refugiados nos países desenvolvidos, os quais sempre foram e continuam sendo, o destino preferido de refugiados, se é que estes têm o privilégio de ter preferência.

A legislação brasileira tem facilitado, nos últimos anos, uma recepção benevolente dos refugiados que, paradoxalmente, sofrerão imediatamente as agruras de viver sem o devido apoio governamental, uma vez que não existem políticas públicas específicas para a inserção destes refugiados em nossa sociedade.

Mas, para o bem e para o mal, onde não existe a ação estatal, outros atores tomam para si certas responsabilidades. É o caso de algumas organizações não-governamentais pioneiras, que vem ajudando os refugiados que chegam ao Brasil a se integrarem da melhor forma possível ao país.

\section{Referências}

ANDRADE, José H. Fischel de. Direito internacional dos refugiados: evolução histórica (1921-1952). Rio de Janeiro: Renovar, 1996.

ANDRADE, José H. Fischel de; MARCOLINI, Adriana. Brazil ${ }^{e}$ s Refugee Act: model refugee law for Latin America? Forced Migration Review, 12, p. 37-39, janeiro de 2002. Disponível em: http://www.fmreview.org/sites/fmr/files/FMRdownloads/en/FMRpdfs/FMR12/fmr12full.pdf. Acesso em: 19 mar 2016.

ANNONI, Danielle; VALDES, Lysian Carolina. O Direito Internacional dos Refugiados e o Brasil. Curitiba: Juruá, 2013.

ARENDT, Hanna. Origens do totalitarismo. São Paulo: Companhia das Letras, 2012. ARNAUD, André-Jean. Governar sem fronteiras: entre globalização e pós-globalização crítica da razão jurídica. Rio de Janeiro: Lumen Juris, 2007. 
BOBBIO, Norberto. Estado, Governo, Sociedade: Para uma teoria geral da política. São Paulo: Paz \& Terra, 2014.

BYRNE, Rosemary (coord.). The Refugee Law Reader Cases, Documents, and Materials. 4a ed., Budapest: Hungarian Helsinki Committee, Janeiro de 2008. Disponível em: http://www.refworld.org/pdfid/478f22f12.pdf. Acesso em 14 mar 2016.

COUTINHO, Leonardo. Bem vindos ao Brasil...e virem-se. Veja. São Paulo: Editora Abril, edição 2429, ano 48, n. 23, 10 jun 2015, p.94-95.

GOHN, Maria da Glória. O protagonismo da sociedade civil: movimentos sociais, ONGs e redes solidárias. 2.ed. São Paulo: Cortez, 2008.

HAYDU, Marcelo. A integração dos refugiados no Brasil. In: In: RAMOS, André de Carvalho; RODRIGUES, Gilberto; ALMEIDA, Guilherme Assis de. (orgs.) 60 anos de ACNUR: perspectivas de futuro. São Paulo: CLA Cultural/ACNUR/ANDHEP, 2011. p.131145 .

HOBSBAWN, Eric. Era dos Extremos: o breve século XX - 1914-1991. $2^{\mathrm{a}}$ ed., 41 reimpressão, São Paulo: Companhia das Letras, 2009.

HOURANI, Albert. Uma História dos Povos Árabes. $2^{\mathrm{a}}$ ed., $7^{\mathrm{a}}$ reimpressão, São Paulo: Companhia das Letras, 2001.

JAEGER, Gilbert. On the history of the international protection of refugees. IRRC International Reviewof the Red Cross, Setembro de 2001, vol. 83, n. 843, p. 727 (tradução dos autores). Disponível em: https://www.icrc.org/eng/assets/files/other/727_738 jaeger.pdf. Acesso em: 16 mar 2016.

JUBILUT, Liliana Lyra. O Direito Internacional dos Refugiados e sua Aplicação no Ordenamento Jurídico Brasileiro. São Paulo: Método, 2007. Disponível em: http://www.acnur.org/t3/fileadmin/Documentos/portugues/Publicacoes/2013/O_Direito_Inter nacional_dos_Refugiados.pdf?view=1. Acesso em: 03 mar 2016.

LIMA, Manoel Hermes de. Organizações não governamentais defensoras dos direitos humanos: ONGs internacionais como prováveis sujeitos de direito internacional. Curitiba: Appris, 2014.

MIALHE, Jorge Luís. Entre Clio e Themis: Gérmens do Direito Internacional na Antiguidade. Cadernos Jurídicos: Curso de Direito Unisal. Campinas Ano I (2010). Campinas: Millennium, 2010, p.207-234.

NASCIMENTO, Luiz Sales do. A cidadania dos refugiados no Brasil. 2a . Ed. São Paulo: Verbatim, 2014.

ONU. Convenção Relativa ao Estatuto dos Refugiados das Nações Unidas. Disponível em:<

http://www.pge.sp.gov.br/centrodeestudos/bibliotecavirtual/instrumentos/refugiados.htm>. Acesso em: 27 mar. 2016 
PANIZZA, Diego. Introdução ao Direito de Guerra. In: GENTILI, Alberico. O Direito de Guerra (De iure belli libri três). Tradução de Ciro Mioranza. Ijuí: Editora UNIJUÍ/Fondazione Cassamarca, 2005.

PIOVESAN, Flávia. O direito de asilo e a proteção internacional dos refugiados. In: ARAUJO, Nádia de; ALMEIDA, Guilherme de Assis (orgs.). O Direito Internacional dos Refugiados: uma perspectiva brasileira. Rio de Janeiro: Renovar, 2001, p.27-64.

POLETTO, Ivo; ADAMS, Telmo (org.). Cáritas na promoção da solidariedade: como organizar a ação caritas. Brasília: Cáritas Brasileira, 2005. Disponível em: <http://caritas.org.br/wp-content/uploads/2011/03/cartilha-c\%C3\%A1ritas-na-base\%C3\%BAltima-vers\%C3\%A3o.pdf>. Acesso em: 16 mar. 2016.

RAMOS, André de Carvalho; RODRIGUES, Gilberto; ALMEIDA, Guilherme Assis de. (orgs.) 60 anos de ACNUR: perspectivas de futuro. São Paulo: CLA Cultural/ACNUR/ANDHEP, 2011.

RODRIGUES, Gilberto M.A. O futuro do refúgio no Brasil e seu papel no cenário humanitário. In: BARRETO, Luiz Paulo Teles Ferreira (org.). Refúgio no Brasil: a proteção brasileira aos refugiados e seu impacto nas Américas. Brasília: ACNUR, Ministério da Justiça, 2010. Disponível em:http://www.justica.gov.br/central-deconteudo/estrangeiros/livrorefugiobrasil.pdf/view. Acesso em: 17 mar 2016.

SERRAGLIO, Diogo Andreola. A proteção dos refugiados ambientais pelo direito internacional: uma leitura a partir da teoria da sociedade de risco. Curitiba: Juruá, 2014.

SOCZEK, Daniel. Ongs e Democracia: Metamorfoses de um Paradigma em Construção. Curitiva: Juruá, 2007.

\section{Sites}

ACNUR - Alto Comissariado das Nações Unidas para Refugiados. Disponível em: <http://www.acnur.org/t3/portugues $>$. Acesso em: 10 mar 2016.

ADUS - Instituto de Reintegração do Refugiado-Brasil.Disponível em: <http://www.adus.org.br/>. Acesso em: $17 \mathrm{fev} 2016$.

BIBLIASPA - Biblioteca e Centro de Pesquisa América do Sul-Países Árabes. Disponível em: <http://bibliaspa.org>. Acesso em: 07 mar 2016.

CÁRITAS. Disponível em: <caritas.org.br>. Acesso em: 19 mar 2016.

CONARE - Comitê Nacional para os Refugiados. Disponível em: <http://portal.mj.gov.br/data/Pages/MJ7605B707ITEMID5246DEB0F8CB4C1A8B9B54B47 3B697A4PTBRIE.htm>. Acesso em: $14 \mathrm{fev} 2016$.

IKMR. Disponível em: 〈http://www.ikmr.org.br/>. Acesso em: 07 mar 2016.

IMDH - Instituto Migrações e Direitos Humanos. Disponível em: < http://migrante.org.br/. Acesso em: 21 mar 2016. 
THE HUGUENOT SOCIETY OF GREAT BRITAIN \& IRELAND. Disponível em: <http://www.huguenotsociety.org.uk/history.html>. Acesso em: 14 mar 2016.

UNITED NATIONS - $\quad$ UN. Disponível

<http://www.un.org/en/documents/charter/chapter10.shtml>. Acesso em: 19 mar 2016.

UNHCR - The UN Refugee Agency.Disponível em: <http://www.unhcr.org>. Acesso em: 07 mar 2016.

UNHCR - Apêndice da Convenção de 1933 da Liga das Nações. Disponível em: http://www.refworld.org/cgi-bin/texis/vtx/rwmain?docid=3dd8cf374. Acesso em: 03 mar 2016.

UNHCR - Relatório de Revisão Periódica Universal da Divisão de Proteção Internacional Maio 2012. Disponível em: 〈http://www.refworld.org/pdfid/4ed360b12.pdf>. Acesso em: 13 $\operatorname{mar} 2016$. 